\title{
Metode Asosiasi Data Mining Untuk Analisa Persediaan Fiber Optik Menggunakan Algoritma Apriori
}

\author{
Novalia Barkah $^{1}$, Entin Sutinah ${ }^{2 *}$, Nani Agustina ${ }^{3}$ \\ ${ }^{1}$ Sistem Informasi; STMIK Nusa Mandiri; JIn. Jatiwaringin Raya No.02 RT08 RW 013 \\ Kelurahan Cipinang Melayu Kecamatan Makassar Jakarta Timur, 021- 28534236, 28534471, \\ 28534390; e-mail: novalia.sps@gmail.com \\ 2 Fakultas Teknik dan Informatika; Universitas Bina Sarana Informatika; Jl. Kramat \\ Raya No.98, Senen, Jakarta Pusat 10450, (021) 23231170, Fax. (021) 21236158; e-mail: \\ entin.esh@bsi.ac.id \\ ${ }^{3}$ Fakultas Teknik dan Informatika; Universitas Bina Sarana Informatika; JI. Kramat \\ Raya No.98, Senen, Jakarta Pusat 10450, (021) 23231170, Fax. (021) 21236158; e-mail: \\ nani.nna@bsi.ac.id \\ *Korespondensi: e-mail: entin.esh@bsi.ac.id
}

\begin{abstract}
PT. Bahana Arta Nusantara is a telecommunications contractor company. The need for fiber optic goods is increasing, cause difficulty to see itemset patterns that often come out together. Besides that, PT. Bahana Arta Nusantara also has difficulty maximizing data on goods expenditure because the data is only stored without a more detailed analysis. The purpose of this study was to determine the pattern of outgoing goods data that often came out at the same time using the Apriori Algorithm (Association Rule). The determination of this association is done by determining the binary representation of the optical goods expenditure data, looking for the value of the two itemsets combination pattern, the three itemsets combination pattern and then the final calculation of the association rules to determine the maximum and objective results, so that the results of this pattern the company can provide goods are often out together, and not following the stock event.
\end{abstract}

Keywords: Algoithm, Apriori, Association, Data mining, Inventory

\begin{abstract}
Abstrak
PT. Bahana Arta Nusantara merupakan perusahaan yang bergerak dibidang kontraktor telekomunikasi. Kebutuhan akan barang-barang fiber optik semkin meningkat sehingga menyebabkan kesulitan untuk mengetahui pola itemset yang sering keluar secara bersamaaan. Selain itu PT. Bahana Arta Nusantara juga mengalami kesulitan dalam memaksimalkan pemanfaatan data pengeluaran barang fiber optik dikarenakan data tersebut hanya disimpan tanpa dianalisa secara lebih detail. Tujuan dari penelitian ini untuk mengetahui pola data barang keluar yang sering keluar dalam waktu bersamaan dengan menggunakan Algoritma Apriori (Association Rule). Penentuan asosiasi ini dilakukan dengan cara menentukan representasi biner data pengeluaran barang fiber optik, mencari nilai pola kombinasi dua itemset, pola kombinasi tiga itemsets dan kemudian dilakukan perhitungan final aturan asosiasi untuk menentukan hasil yang maksimal dan objektif, sehingga hasil dari pola ini perusahaan dapat menyediakan barang yang sering keluar secara bersamaan supaya tidak kehabisan stok barang.
\end{abstract}

Kata kunci: Algoitma, Apriori, Asosiasi, Data mining, Persediaan 


\section{Pendahuluan}

Jasa pemasangan fiber optik sangat berpengaruh dalam perkembangan teknologi. Melihat perkembangan permintaan konsumen maka hal ini dapat meningkatkan persaingan di dunia perdagangan menjadi semakin ketat.

Proses kegiatan penjualan berjalan terus dan menghasikan juga data yang semakin bertambah. Data-data penjualan yang semakin lama maka jumlahnya akan besar tidak akan berguna dan bermanfaat jika dibiarkan begitu saja. Supaya data tersebut menjadi data berguna maka diperlukan pengolahan data dengan suatu algoritma tertentu. Algoritma apriori bagian dari data mining yaitu kegiatan pengumpulan data dengN pemakaian data yang lama untuk menemukan keteraturan pola atau keterkaitan dalam suatu data (Purba et al., 2018).

Agar dapat bersaing dengan para pebisnis lain di bidang yang sama, sehingga hal ini pun harus mewajibkan para pengusaha harus bisa memaksimalkan pemanfaatan data, dan harus bisa lebih menganalisa data tersebut tidak hanya disimpan.

Teknik Data mining digunakan untuk mengatasi permasalahan tentang banyaknya jumlah data yang ada, salah satunya dengan penerapan algoritma apriori untuk mendapatkan informasi tentang asosiasi antar produk dari suatu database transaksi. Data transaksi penjualan kemudian diolah dengan menggunakan aplikasi Data mining sehingga didapat aturan asosiasi keterkaitan yang kuat antar itemset penjualan suku cadang dan dapat menghasilkan rekomendasi penyetokan barang serta mempermudah penataan atau penempatan barang yang kuat berkaitan saling ketergantungan (Ummi, 2015).

Penerapan algoritma apriori diharapkan akan menemukan berupa produk yang sering dibeli bersamaan. Pola tersebut digunakan untuk menempatkan produk yang sering dibeli bersamaan dalam sebuah area yang saling berdekatan. Adapun hasil yang dicapai berupa laporan hasil data minng pola pembelian barang yang sering dibeli secara bersamaan guna pengembangan strategi pemasaran dalam penjualan barang.

Dalam proses intalasi banyak membutuhkan komponen-komponen perangkat sehingga membutuhkan bantuan teknologi dengan mengadakan dengan skema apriori (Santoso et al., 2016).

PT. Bahana Arta Nusantara yang bergerak dibidang kontraktor telekomunikasi kendala yang sering dihadapi kesulitan dalam melakukan pencatatan keluar barang seiring dengan berkembangnya perusahaan tersebut, mengatur pola dalam mengetahui itemset mana saja yang sering digunakan dalam waktu bersamaan juga sulit. Dimana pemesanan semakin banyak sehingga kebutuhan akan barang-barang fiber optik pun semakin meningkat untuk pemasangan site, dengan mengandalkan kualitas barang fiber optik beserta kualitas dalam instalasi pemasangan yang mampu bersaing dengan perusahaan kontraktor telematika lainnya.

Dengan adanya permasalahan yang kami temukan PT. Bahana Arta Nusantara belum dapat mengatur pola dalam mengetahui itemset barang, memaksimalkan pemanfaatan data, dan data pengeluaran hanya disimpan tanpa dianalisa secara lebih detail, terlebih lagi 
mengalami kesulitan dalam pemesanan barang untuk pemasangan site, sehingga pada data pengeluaran barang belum mengetahui pola dari data pengeluaran tersebut.

\section{Data Mining}

Selain dari pengertian yang telah dijelaskan pada latar belakang, Data Mining disebut juga Knowledge Discovery in Database (KDD) didefenisikan sebagai ekstraksi informasi potensial, implisit dan tidak dikenal dari sekumpulan data (Tampubolon et al., 2013).

Suatu proses mendapatkan informasi berguna dari gudang basis data yang besar disebut Data Mining. Atau dalam kata lain merupakan informasi yang didapat dari bongkahan data besar yang dapat membantu dalam pengambilan keputusan (Praseyto, 2013).

Interestingness measure yang dapat digunakan data mining adalah: Support adalah ukuran yang menunjukan tingkat ukuran besaran dominasi dari item atau itemset dari total transaksi dan Confidence suatu ukuran dimana menampilkan hubungan antar dua item secara conditonal (Ummi, 2015)

Ada beberapa macam pendekatan yang berbeda yang diklasifikasikan sebagai teknik pencarian informasi/pengetahuan dalam KDD. Ada pendekatan kuantitatif, seperti pendekatan probabilistik seperti logika induktif, pencarian pola, dan analisis pohon keputusan. Pendekatan yang lain meliputi deviasi, analisis kecenderungan, algoritma genetik, jaringan saraf tiruan, dan pendekatan campuran dua atau lebih dari beberapa pendekatan yang ada. Pada dasarnya ada enam elemen yang paling esensial dalam teknik pencarian informasi/pengetahuan dalam KDD yaitu: mengerjakan sejumlah besar data, diperlukan efesiensi berkaitan dengan volume data, mengutamakan ketetapan/ keakuratan, membutuhkan pemakaian bahasa tingkat tinggi, menggunakan beberapa bentuk dari pembelajaran otomatis, menghasilkan hasil yang menarik.

\section{Fungsi dan Tugas Data Mining}

\section{Association Rule}

Association rules merupakan teknik dari data mining untuk menentukan hubungan antar item pada sekumpulan data yang telah di tetapkan. Konsep ini sendiri diturunkan dari terminologi market basket analysis, yaitu pencarian hubungan daribeberapa produk di dalam transaksi pembelian (Wijayanti, 2017).

Algoritma aturan asosiasi akan menggunakan data latihan, sesuai dengan pengertian Data Mining, untuk menghasilkan pengetahuan. Pengetahuan untuk mengetahui item-item belanja yang sering dibeli secara bersamaan dalam suatu waktu. Aturan asosiasi yang berbentuk "if...then..." atau "jika...maka..." merupakan pengetahuan yang dihasilkan dari fungsi aturan asosiasi.Aturan ini dihitung dari data yang sifatnya probabilistik (Sepri \& Afdal, 2017).

\section{Tahapan Association Rule}

Analisis asosiasi disebut juga sebagai bagian dari teknik data mining yang dijadikan dasar dari berbagai teknik data mining yang lainya. Tahap asosiasi disebut juga analisis pola frekuensi tinggi (frequent pattern mining) dan menjadi daya tarik para peneliti untuk mengahasilkan suatu algoritma yang efisien. Dua tahap metodologi dasar analisis asosiasi yaitu: 
a. Analisa pola frekuensi tinggi

Analisa pola frekuensi tinggi digunakan untuk mencari kombinasi item yang memenuhi syarat minumum dari nilai support yang terdapat dalam database. Nilai support sebuah item diperoleh dengan memakai rumus berikut:

Support $(\mathrm{A})=$

JumlahTrassaksiMengandung $A$

TotalTransaksi

Sedangkan nilai dari support dua item diperoleh dari rumus berikut:

Support $(\mathrm{A}, \mathrm{B})=(\mathrm{A} \cap \mathrm{B})$

JumlahTransaksiMengandungAdanB

TotalTransaksi

b. Pembentukan Aturan Asosiasi

Pembentukan aturan asosiasi dapat dilakukan jika semua pola frekuensi tinggi telah ditemukan, maka langkah selanjutnya mencari aturan asosiatif yang memenuhi syarat minimum dengan menggunakan rumus:

Confidence $=\mathrm{P}(\mathrm{B} \mid \mathrm{A})=$

JumlahTransaksiMengandungAdanB

TotalTransaksi

Pembentukan Association Rule Mining

Rumus Association Rule sebagai berikut :

$R=3^{d}-2^{d+1+1}$ (Kusrini \& Luthfi, 2010)

\section{Algoritma Apriori}

Algoritma apriori merupakan algoritma dasar yang diusulkan menentukan Frequent item sets untuk menentukan aturan asosiasi Boolean. (Listriani et al., 2018) Algoritma Apriori merupakan jenis Aturan Asosiasi pada bagian data mining. Aturan dalam menyatakan asosiasi disebut affinity analysis atau market basket analysis. Association rule mining atau Analisis asosiasi bagian dari teknik data mining dalam menetukan aturan untuk memodifikasi suatu kombinasi item. Tahap analisis asosiasi salah satu dengan tujuan mendapatkan algoritma efisien dengan mendapatkan analisis pola frequensi tinggi (frequent pattern mining).

\section{Metode Penelitian}

Metode penelitian ini menjelaskan mengenai tahapan penelitian, instrumen penelitian, pengumpulan data, populasi penelitan dan sampel penelitian.

Tahapan penelitian

Tahapan penelitian 
Tahapan penelitian merupakan urutan-urutan dalam melakukan penelitian dari awal ampai akhir penelitian. Tahapan-tahapan dalam penelitian ini dapat di gambarkan dalam bentuk flowchart seperti pada gambar 1.

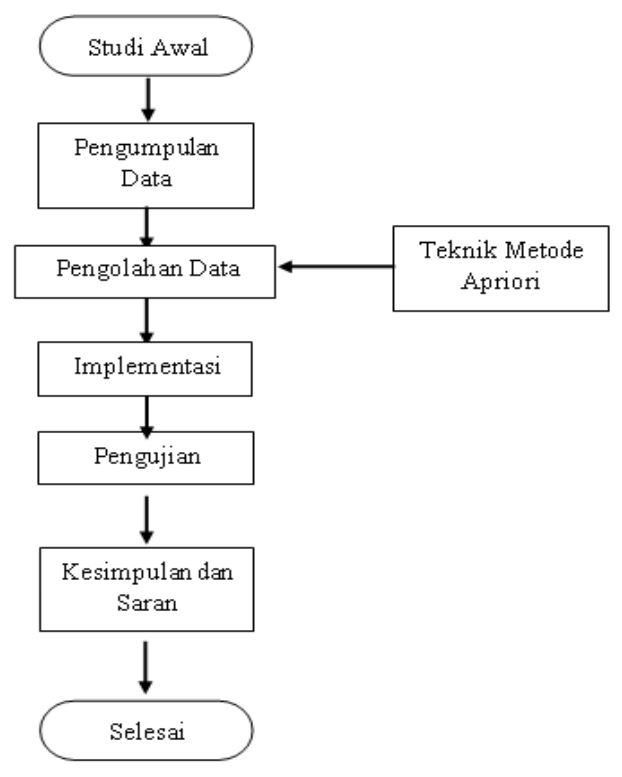

Sumber : (Tampubolon et al., 2013)

Gambar 1 Flowchart Penelitian

\section{Instrumen Penelitian}

Penelitian dilakukan di PT. Bahana Arta Nusantara dengan tujuan untuk mengetahui data pencatatan dalam pengeluaran kabel fiber optik apakah pencatatan yang dilakukan oleh PT. Bahana Arta Nusantara selama ini sudah balance dan memenuhi sesuai syarat dan ketentuan dalam pengolahan data. Dengan dilakukanya penelitian ini maka diharapkan dapat diketahui dimana letak kesalahan dalam pencatatan data pengeluaran kabel fiber optik di PT. Bahana Arta Nusantara.

\section{Metode Pengumpulan Data, Populasi dan Sample Penelitian}

Metode Pengumpulan Data suatu proses penting dalam penelitian untuk memperoleh informasi dan pengumpulan data yang konkrit dan benar adanya. Tentunya di analisa kembali sesuai dengan masalah yang ada pada perusahaan yang di analisa.

\section{Metode Pengumpulan Data}

\section{Wawancara}

Wawancara diperlukan oleh penulis guna menanyakan secara langsung tentang apa saja masalah yang sering dihadapi oleh pihak perusahaan khususnya tentang persediaan barang fiber optic karena data tersebut dapat digunakan sebagai salah satu sumber pertimbangan dalam pengambilan keputusan. Penulis melakukan tanya jawab dengan manager PT. Bahana Arta Nusanatara untuk memperoleh data apa saja yang dapat menunjang hasil penelitian ini.

2. Pengamatan/Observasi 
Submitted: 5 Agustus 2020; Revised: 20 Agustus 2020; Accepted: 16 September 2020; Published: 30 September 2020

Sebagai metode ilmiah observasi dapat diartikan sebagai pengamatan. Observasi merupakan suatu penyelidikan yang dilakukan secara sistematik dan sengaja dilakukan dengan menggunakan alat indera terutama mata terhadap kejadian yang sedang berlangsung dan dapat dianalisa pada waktu kejadian itu terjadi. Penelitian ini dengan melakukan pengamatan terhadap objek data ddimana bertujuan mendapatkan korelasi antara persediaan dengan kebutuhan, permintaan dan lain-lain.

\section{Dokumentasi}

Motode dokumentasi dilakukan dengan mencari data mengenai hal-hal atau variabel berupa catatan buku manual pengeluaran barang yang dicatat menggunakan Ms, Excel, Data pemasangan nama site, dan sebagainya baik yang berupa file atau dokumen. Dalam hal ini penulis melakukan pengumpulan dokumentasi berupa dokumentasi file data atau data faktur barang keluar untuk digunakan sebagai bahan implementasi dan uji coba.

\section{Populasi}

Dalam hal ini populasi yang digunakan sebagai bahan penelitian yaitu bagian gudang yang mengolah data keluar masuk barang fiber optic.

\section{Sampel Penelitian}

Pengambilan sampel dalam 1 tahun terdapat 14 item barang dan dalam penelitian ini menggunakan teknik Association rule mining.

\section{Metode Analisa Data}

Metode analisa data diartikan sebagai upaya data yang sudah tersedia kemudian diolah dengan statistic dan dapat digunakan untuk menjawab rumusan masalah dalam penelitian. Berhubungan dengan studi kasus pada PT. Bahana Arta Nusantara, dapat dilakukan analisis data. Analisis data dilakukan khusus pada pengeluaran (data fiber optic) dengan tujuan untuk menemukan pola pencatatan kabel fiber optic dan hubungan antar item jenis fiber optic didalam transaksi. Berikut ini adalah table 1 sebagai sampel data dan sebagian terlampir yang akan dijadikan untuk analisa dan juga untuk uji coba. Tentunya hal ini berkaitan dengan bagaimana cara mendapatkan sumber datanya, dan alat apa saja yang digunakan penulis dalam melakukan penelitian. Dalam penulisan penelitian ini, penulis menggunakan 1 (satu) metode pengumpulan data, yaitu data primer.

\section{Data Primer}

Data Primer berasal dari data yang didapat sendiri oleh perorangan atau suatu organisai secara langsung dari objek yang diteliti dan untuk kepentingan studi yang bersangkutan dapat berupa wawancara langsung dengan pimpinan serta pada bagian yang menangani langsung permasalahan di lapangan serta observasi kegiatan sehari-hari suatu objek yang diteliti.

Hasilnya dapat berbentuk data yang dibutuhkan atau data yang diharapkan sesuai dengan penelitian yang dilakukan, seperti data transaksi pengeluaran barang tertentu yang nantinya akan digunakan sebagai bahan analisis data mining. 


\section{Hasil dan Pembahasan}

Penelitian ini membahas mengenai pola pada transaksi pengeluaran barang fiber optik sehingga diketahui jenis fiber optik yang sering keluar pada saat bersamaan.

\subsection{Analisis Data}

Pada tahap analisa ini akan ditampilkan data pola transaksi pengeluaran fiber optic, berdasarkan data transaksi pada periode Januari sampai dengan Desember 2017, Selanjutnya membuat tabulasi data pengeluaran. Pada data pengeluaran fiber optic dibentuk tabel yang akan mempermudah dalam mengetahui berapa banyak item yang di butuhkan dalam setiap pengeluaran pemasangan site.

\subsection{Representasi itemset}

Pada Tahap pengolahan data ini akan ditampikan dari analisa Data pengeluaran fiber optic selama Periode Januari - Desember kemudian diproses dalam pembentukan itemset sehingga menghasilan kombinasi terpilih dari rekap pengeluaran 1 (satu) Tahun.

Tabel 1. Rekap Pengeluaran Tahun

\begin{tabular}{|c|c|c|c|c|c|c|c|c|c|c|c|c|c|c|}
\hline Bulan & $\begin{array}{l}\text { Kab } \\
\text { el } \\
24 C\end{array}$ & $\begin{array}{c}\mathrm{Kab} \\
\mathrm{el} \\
48 \mathrm{C}\end{array}$ & $\begin{array}{c}\text { Kab } \\
\text { el } \\
4 C\end{array}$ & $\begin{array}{c}\text { Tian } \\
g\end{array}$ & $\begin{array}{l}\text { susp } \\
\text { en }\end{array}$ & $\begin{array}{l}\text { Wire } \\
\text { Cla } \\
\mathrm{mp}\end{array}$ & $\begin{array}{c}\text { Slack } \\
\text { hang } \\
\text { er }\end{array}$ & $\begin{array}{l}F \\
A \\
T\end{array}$ & $\begin{array}{l}\text { Pigt } \\
\text { ail }\end{array}$ & $\begin{array}{l}\mathrm{O} \\
\mathrm{T} \\
\mathrm{B}\end{array}$ & $\begin{array}{c}\text { SubDu } \\
\text { ct }\end{array}$ & $\begin{array}{l}\text { Sing } \\
\text { le } \\
\text { Way }\end{array}$ & $\begin{array}{c}\text { Konekt } \\
\text { or }\end{array}$ & $\begin{array}{c}\text { Box } \\
\text { Pan } \\
\text { el } \\
\text { with } \\
\text { mcb }\end{array}$ \\
\hline Januari & $\begin{array}{c}715 \\
0\end{array}$ & $\begin{array}{c}450 \\
0\end{array}$ & 0 & 144 & 129 & 18 & 4 & 0 & 0 & 0 & 0 & 0 & 0 & 0 \\
\hline Februari & $\begin{array}{c}340 \\
0\end{array}$ & $\begin{array}{c}175 \\
0\end{array}$ & 0 & 59 & 59 & 30 & 2 & $\begin{array}{l}1 \\
0\end{array}$ & 10 & 10 & 10 & 10 & 2 & 2 \\
\hline Maret & $\begin{array}{c}395 \\
0\end{array}$ & $\begin{array}{c}120 \\
0\end{array}$ & 0 & 74 & 74 & 68 & 2 & 9 & 9 & 9 & 9 & 9 & 2 & 2 \\
\hline April & $\begin{array}{c}690 \\
0\end{array}$ & $\begin{array}{c}280 \\
0\end{array}$ & 0 & 97 & 97 & 20 & 0 & 0 & 0 & 0 & 0 & 0 & 0 & 0 \\
\hline Mei & $\begin{array}{c}535 \\
0\end{array}$ & 300 & 0 & 181 & 181 & 68 & 5 & 1 & 1 & 1 & 1 & 1 & 5 & 5 \\
\hline Juni & $\begin{array}{c}185 \\
0\end{array}$ & $\begin{array}{c}130 \\
0\end{array}$ & 0 & 35 & 35 & 20 & 0 & 0 & 0 & 0 & 0 & 0 & 0 & 0 \\
\hline July & 500 & 0 & 0 & 37 & 37 & 0 & 1 & 0 & 0 & 0 & 0 & 0 & 0 & 0 \\
\hline Agustus & $\begin{array}{c}415 \\
0 \\
\end{array}$ & 0 & 800 & 146 & 146 & 68 & 1 & 0 & 0 & 0 & 0 & 0 & 0 & 0 \\
\hline $\begin{array}{l}\text { Septem } \\
\text { ber }\end{array}$ & $\begin{array}{c}265 \\
0\end{array}$ & 0 & 0 & 29 & 29 & 20 & 2 & 0 & 0 & 0 & 0 & 0 & 0 & 0 \\
\hline Oktober & $\begin{array}{c}130 \\
0\end{array}$ & 0 & $\begin{array}{c}380 \\
0\end{array}$ & 21 & 21 & 18 & 5 & 3 & 3 & 3 & 3 & 3 & 5 & 5 \\
\hline $\begin{array}{l}\text { Novemb } \\
\text { er }\end{array}$ & $\begin{array}{c}355 \\
0\end{array}$ & 0 & 0 & 97 & 97 & 68 & 2 & 0 & 0 & 0 & 0 & 0 & 0 & 0 \\
\hline $\begin{array}{l}\text { Desem } \\
\text { ber }\end{array}$ & $\begin{array}{c}335 \\
0\end{array}$ & $\begin{array}{c}122 \\
00\end{array}$ & 5 & 113 & 113 & 8 & 2 & $\begin{array}{l}1 \\
0\end{array}$ & 10 & 10 & 10 & 10 & 2 & 2 \\
\hline
\end{tabular}

Sumber : Hasil Penelitian (2018) 
Tabel 2. Representasi pengelompokan Itemset

\begin{tabular}{lll}
\hline No & Kode & \\
\hline 1 & A & Kabel 24 Core \\
\hline 2 & B & Kabel 48 Core \\
\hline 3 & C & Kabel 4 Core \\
\hline 4 & D & Tiang \\
\hline 5 & E & Suspen \\
\hline 6 & F & Wire Clamp \\
\hline 7 & G & Slack Hanger \\
\hline 8 & H & FAT \\
\hline 9 & I & Pigtail \\
\hline 10 & J & OTB \\
\hline 11 & K & Subduct \\
\hline 12 & L & Singleway \\
\hline 13 & M & Konektor \\
\hline 14 & N & Box Panel with MCB \\
\hline
\end{tabular}

Sumber : Hasil Penelitian (2018)

Sebagai sample diambil berdasarkan data pengeluaran pada bulan Januari - Desember 2017 berlaku untuk semua jenis fiber optic dilakukan akumulasi data pengeluaran barang seperti pada tabel 3 .

Tabel 3. Representasi data pengeluaran fiber optic

\begin{tabular}{cc}
\hline Bulan & Item \\
\hline Januari & $\mathrm{A}, \mathrm{B}, \mathrm{D}, \mathrm{E}, \mathrm{F}, \mathrm{G}$ \\
\hline Februari & $\mathrm{A}, \mathrm{B}, \mathrm{D}, \mathrm{E}, \mathrm{F}, \mathrm{G}, \mathrm{H}, \mathrm{I}, \mathrm{J}, \mathrm{K}, \mathrm{L}, \mathrm{M}, \mathrm{N}$ \\
\hline Maret & $\mathrm{A}, \mathrm{B}, \mathrm{D}, \mathrm{E}, \mathrm{F}, \mathrm{G}, \mathrm{H}, \mathrm{I}, \mathrm{J}, \mathrm{K}, \mathrm{L}, \mathrm{M}, \mathrm{N}$ \\
\hline April & $\mathrm{A}, \mathrm{B}, \mathrm{D}, \mathrm{E}, \mathrm{F}$ \\
\hline Mei & $\mathrm{A}, \mathrm{B}, \mathrm{D}, \mathrm{E}, \mathrm{F}, \mathrm{G}, \mathrm{H}, \mathrm{I}, \mathrm{J}, \mathrm{K}, \mathrm{L}, \mathrm{M}, \mathrm{N}$ \\
\hline Juni & $\mathrm{A}, \mathrm{B}, \mathrm{D}, \mathrm{E}, \mathrm{F}$ \\
\hline July & $\mathrm{A}, \mathrm{E}, \mathrm{F}, \mathrm{G}$ \\
\hline Agustus & $\mathrm{A}, \mathrm{C}, \mathrm{D}, \mathrm{E}, \mathrm{F}, \mathrm{G}$ \\
\hline Bulan & $\mathrm{Item}$ \\
\hline September & $\mathrm{A}, \mathrm{D}, \mathrm{E}, \mathrm{F}, \mathrm{G}$ \\
\hline Oktober & $\mathrm{A}, \mathrm{C}, \mathrm{D}, \mathrm{E}, \mathrm{F}, \mathrm{G}, \mathrm{H}, \mathrm{I}, \mathrm{J}, \mathrm{K}, \mathrm{L}, \mathrm{M}, \mathrm{N}$ \\
\hline November & $\mathrm{A}, \mathrm{D}, \mathrm{E}, \mathrm{F}, \mathrm{G}$ \\
\hline Desember & $\mathrm{A}, \mathrm{B}, \mathrm{C}, \mathrm{D}, \mathrm{E}, \mathrm{F}, \mathrm{G}, \mathrm{H}, \mathrm{I}, \mathrm{J}, \mathrm{K}, \mathrm{L}, \mathrm{M}, \mathrm{N}$ \\
\hline
\end{tabular}

Sumber: Hasil Penelitian (2018) 
Pada data pengeluaran fiber optic dibentuk tabel tabular yang akan memudahkan dalam mengetahui beberapa item yang dikeluarkan.

Tabel 4. Representasi biner data pengeluaran

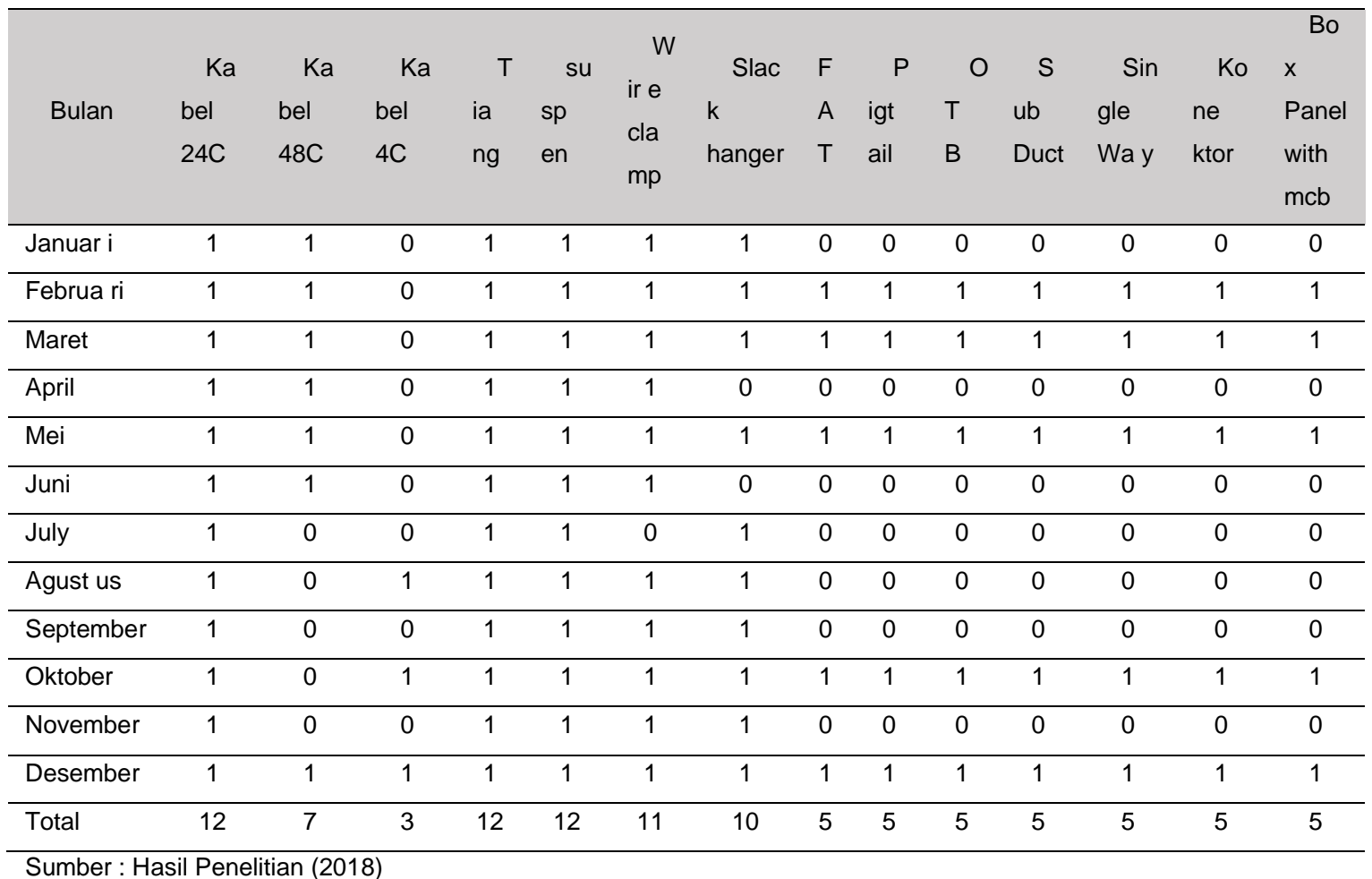

\subsection{Penentuan Association Rule Mining}

Pada tahap ini menggunakan data pada tabel Representasi Biner data pengeluaran selama 1 (satu) tahun, dengan jumlah itemd=12, maka jumlah kemungkinan rule adalah sebesar :

$$
\begin{aligned}
& R=3^{d}-2^{d+1}+1 \\
& R=3^{12}-2^{12+1}+1 \\
& R=3^{12}-2^{13+1} \\
& R=531.441-8192+1 \\
& R=531.441-8193 \\
& R=523.248 .
\end{aligned}
$$

\subsection{Pembentukan Itemset}

Penyelesaian berdasarkan tabel yang sudah disediakan pada tabel 4 proses pembentukan $\mathrm{C} 1$ atau disebut dengan 1 item dengan jumlah minimum support $=52.36 \%$.

Tabel 5. Support dari setiap item

\begin{tabular}{cccc}
\hline Kode & $\begin{array}{c}\text { Nama } \\
\text { Item }\end{array}$ & Jumlah & Support \\
\hline A & $\begin{array}{l}\text { Kabel } 24 \\
\text { Core }\end{array}$ & 12 & $\mathbf{8 5 . 7 1 \%}$ \\
\hline
\end{tabular}




\begin{tabular}{|c|c|c|c|}
\hline Kode & $\begin{array}{c}\text { Nama } \\
\text { Item }\end{array}$ & Jumlah & Support \\
\hline B & $\begin{array}{l}\text { Kabel } 48 \\
\text { Core }\end{array}$ & 7 & $50 \%$ \\
\hline C & $\begin{array}{l}\text { Kabel } 4 \\
\text { Core }\end{array}$ & 3 & $21.43 \%$ \\
\hline $\mathrm{D}$ & Tiang & 12 & $85.71 \%$ \\
\hline$E$ & Suspen & 12 & $85.71 \%$ \\
\hline$F$ & $\begin{array}{l}\text { Wire } \\
\text { Clamp }\end{array}$ & 11 & $78.57 \%$ \\
\hline $\mathrm{G}$ & $\begin{array}{l}\text { Slack } \\
\text { Hanger }\end{array}$ & 10 & $71.43 \%$ \\
\hline $\mathrm{H}$ & FAT & 5 & $35.71 \%$ \\
\hline 1 & Pigtail & 5 & $35.71 \%$ \\
\hline$J$ & OTB & 5 & $35.71 \%$ \\
\hline $\mathrm{K}$ & Subduct & 5 & $35.71 \%$ \\
\hline L & $\begin{array}{l}\text { Single } \\
\text { way }\end{array}$ & 5 & $35.71 \%$ \\
\hline M & Konektor & 5 & $35.71 \%$ \\
\hline $\mathrm{N}$ & $\begin{array}{l}\text { Box panel } \\
\text { with } \mathrm{MCB}\end{array}$ & 5 & $35.71 \%$ \\
\hline $\begin{array}{l}\text { Total minimum } \\
\text { support }\end{array}$ & & & $=52.36 \%$ \\
\hline
\end{tabular}

Dari proses pembentukan item pada table 5 dengan minimum support $52.36 \%$ dapat diketahui yang memenuhi standar minimum support yaitu : Kabel 24 Core, Tiang, Suspen, Wire Clamp, Slack Hanger. Kemudian dibentuk kombinasi 2 item. Table diatas adalah item data yang memenuhi support minimal, nilai support minimal sama dengan 52.36 persen (\%). Seperti yang terlihat pada tabel 6

Tabel 6. Keterangan Jenis Items Fiber Optic yang memenuhi support minimal

\begin{tabular}{ccc}
\hline Nama Item & Jumlah & Support \\
\hline Kabel 24 Core & 12 & $\mathbf{8 5 . 7 1 \%}$ \\
\hline Tiang & 12 & $\mathbf{8 5 . 7 1 \%}$ \\
\hline Suspen & 12 & $\mathbf{8 5 . 7 1 \%}$ \\
\hline Wire Clamp & 11 & $\mathbf{7 8 . 5 7 \%}$ \\
\hline Slack Hanger & 10 & $\mathbf{7 1 . 4 3 \%}$ \\
\hline
\end{tabular}

Sumber : Hasil Penelitian (2018)

\subsection{Pembentukan Pola Kombinasi Itemsets}

Hasil pembentukan pola kombinasi dibentuk dari item-item set jenis fiber optic yang memenuhi suport minimal dengan mengkombinasikan semua jenis itemset menjadi pola dua itemset. Hasil pembentukan pola kombinasi dapat dilihat pada tabel 7 
Tabel 7. Pola Kombinasi Dua Itemsets

\begin{tabular}{|c|c|c|}
\hline Kode & Jumlah & Support \\
\hline$A, D$ & 12 & $100 \%$ \\
\hline$A, E$ & 12 & $100 \%$ \\
\hline$A, F$ & 11 & $91.67 \%$ \\
\hline$A, G$ & 10 & $83.33 \%$ \\
\hline $\mathrm{D}, \mathrm{E}$ & 12 & $100 \%$ \\
\hline $\mathrm{D}, \mathrm{F}$ & 11 & $91.67 \%$ \\
\hline $\mathrm{D}, \mathrm{G}$ & 10 & $83.33 \%$ \\
\hline $\mathrm{E}, \mathrm{F}$ & 11 & $91.67 \%$ \\
\hline $\mathrm{E}, \mathrm{G}$ & 10 & $83.33 \%$ \\
\hline$F, G$ & 9 & $75 \%$ \\
\hline
\end{tabular}

Sumber : Hasil Penelitian (2018)

Dari kombinasi 2 item dengan minimum support 52,36\% Maka diketahui kombinasi 2 itemset memenuhi standart minimum support yaitu Kabel 24 Core, Tiang, Suspen, Wire Clamp, Slack Hanger. Dan dari kombinasi 2 item akan dibentuk 3 itemset seperti pada tabel 8 :

Tabel 8. Pola Kombinasi Tiga Itemsets

\begin{tabular}{|c|c|c|}
\hline Kode & Jumlah & Support \\
\hline$A, D, E$ & 12 & $100 \%$ \\
\hline$A, D, F$ & 11 & $91.67 \%$ \\
\hline$A, D, G$ & 10 & $83.33 \%$ \\
\hline$A, E, F$ & 11 & $91.67 \%$ \\
\hline$A, E, G$ & 10 & $83.33 \%$ \\
\hline$A, F, G$ & 9 & $75 \%$ \\
\hline
\end{tabular}

Sumber : Hasil Penelitian (2018)

\subsection{Pembentukan Aturan Asosiasi}

Tabel 9. Perhitungan Final Aturan Asosiasi

\begin{tabular}{lcc}
\hline \multicolumn{1}{c}{ Aturan } & Confidence \\
\hline Jika membeli kabel 24 Core dan Tiang, maka akan membeli suspen & $12 / 12$ & $\mathbf{1 0 0}$ \\
\hline & & $12 / 12$ \\
Jika membeli Kabel 24 Core dan Suspen, maka akan membeli Tiang & $\mathbf{1 0 0}$ \\
\hline Jika membeli Tiang dan Suspen, maka akan membeli Kabel 24 Core & $12 / 12$ & $\mathbf{1 0 0}$
\end{tabular}

Sumber : Hasil Penelitian (2018)

Tabel final association rule tersebut didapat bahwa yang harus diperbanyak oleh PT. Bahana Arta Nusantara adalah Kabel 24 Core, Tiang dan Suspen. Perusahan dapat menyusun strategis dalam penentuan yang harus di sediakan dan juga dapat mengatur peletakan itemset yaitu Kabel 24 Core, Tiang dan Suspen yang sudah terbentuk. 


\section{Kesimpulan}

Mengumpulkan data dan membuat pengelempokan data pengeluaran fiber optic pada PT. Bahana Arta Nusantara yang dimana lebih banyak mengeluarkan berdasarkan 14 jenis macam dari fiber optic dan respresentasi data pengeluaran diperoleh 3 itemset fiber optic Kabel 24 Core, Tiang dan Suspen .Proses penentuan pola data pengeluaran dapat dilihat berdasarkan pola kombinasi 2 (dua) dan 3 (tiga) itemsets. Dan PT. Bahana Arta Nusantara dapat mengatur posisi penempatan jenis fiber optic secara berdekatan untuk mempermudah dalam mengatahui yang lebih sering dibutuhkan.Pada penelitian selanjutnya agar dapat dikembangkan dengan perhitungan menggunakan Assosiasi Algoritma Apriori dengan pola kombinasi lebih dari 3 (tiga) itemsets dan data item yang digunakan lebih banyak, karena semakin banyak data item makin akurat untuk hasil perhitungan atau juga dapa menggunakan metode yang lainya yang berkaitan dengan assosiasi data mining seperti FP-Growth (Frequent Pattern Growth).

\section{Daftar Pustaka}

Kusrini, \& Luthfi, E. T. (2010). Algoritma Data Mining. CV. Andi Offset.

Listriani, D., Setyaningrum, A. H., \& Eka, F. (2018). Penerapan Metode Asosiasi Menggunakan Algoritma Apriori Pada Aplikasi Analisa Pola Belanja Konsumen (Studi Kasus Toko Buku Gramedia Bintaro). Jurnal Teknik Informatika, 9(2), 120-127. https://doi.org/10.15408/ji.v9i2.5602

Praseyto, E. (2013). Data Mining: Konsep dan Aplikasi Menggunakan Matlab. Andi Publishesr. Purba, B. R. B., Hasibuan, N. A., Ginting, G. L., \& Suginam, S. (2018). Implementasi Algoritma Apriori Untuk Mencari Relasi Pada Transaksi Pembelian Alat-Alat Kesehatan. JURIKOM (Jurnal Riset Komputer), 5(3), 281-288.

Santoso, H., Hariyadi, I. P., \& Priyatno. (2016). Data Mining Analisa Pola Pembelian Produk. Seminar Nasional Teknologi Informasi Dan Multimedia, 19-24.

Sepri, D., \& Afdal, M. (2017). Analisa Dan Perbandingan Metode Algoritma Apriori Dan FpGrowth Untuk Mencari Pola Daerah Strategis Pengenalan Kampus Studi Kasus Di Stkip Adzkia Padang. Jurnal Sistem Informasi Kaputama (JSIK), 1(1).

Tampubolon, K., Saragih, H., \& Reza, B. (2013). Implementasi Data Mining Algoritma Apriori Pada Sistem Persediaan Alat-Alat Kesehatan. Jurnal Informasi Dan Teknologi (INTI), 1(1), 93-106.

Ummi, K. (2015). Analisa Data Mining Dalam Penjualan Sparepart Mobil Dengan Menggunakan Metode Algoritma Apriori ( Studi Kasus : di PT . IDK 1 Medan ). CSRID Journal, 8(3), 155164.

Wijayanti, A. (2017). Analisis Hasil Implementasi Data Mining Menggunakan Algoritma Apriori pada Apotek. Jurnal Edukasi Dan Penelitian Informatika (Jefin), 3(1), 60-64. 